\title{
Kita adalah Klinisi, bukan Sekedar Penghobi Ultrasonografi: Keterbatasan Ultrasonografi Point-Of-Care Jantung dalam Memandu Resusitasi Cairan
}

\author{
Syahrul Mubarak Danar Sumantri, ${ }^{1}$ Fauzana ${ }^{2}$ \\ ${ }^{1}$ Departemen Anestesiologi dan Critical Care, Rumah Sakit Siloam Jember \\ ${ }^{2}$ Departemen Anestesiologi dan Terapi Intensif, Rumah Sakit Perkebunan PTPN X Jember
}

\begin{abstract}
Abstrak
Pemeriksaan penunjang ultrasonografi point-of-care (POCUS) jantung sangat berguna dalam memandu resusitasi pasien kritis dengan penyakit penyerta jantung. Namun, POCUS jantung memiliki keterbatasan dan harus tetap dipandu pemeriksaan fisis klinis. Seorang perempuan berusia 84 tahun, mendapatkan perawatan di ruang intensif atas indikasi hemodinamik tidak stabil pascaperdarahan akut gastrointestinal bawah. Pasien tampak somnolen, takipnea, hipotensi disertai distensi vena jugularis. Pemeriksaan laboratorium hanya menunjukkan tanda anemia akut, sedangkan pada rontgen toraks didapatkan kardiomegali dan pacu jantung-tanam. Pasien ditemukan di bangsal dalam kondisi hipotensi dan diberikan bolus cairan. Evaluasi pascabolus cairan, pasien menunjukkan tanda hemodinamik stabil yang transien akibat perdarahan yang terus menerus. Dengan kecurigaan awal bahwa terdapat gangguan fungsi jantung maka ekokardiografi digunakan untuk memandu resusitasi cairan. Pada pemeriksaan tidak didapatkan variasi left ventricular outflow tract velocity time integral (VTi) disertai regurgitasi aorta (AR) moderat dan parameter lain yang membatasi fungsi ultrasonografi POCUS jantung dalam memandu uji responsivitas cairan. Penulis akhirnya melakukan resusitasi cairan dengan panduan pemeriksaan klinis secara berulang semata disertai pemeriksaan ultrasonografi inferior vena cava (IVC). Pasien berhasil diresusitasi dengan bolus cairan intravena dalam jumlah besar tanpa komplikasi sekunder. Penilaian klinis tetap diperlukan terutama pada kondisi patologis tertentu yang membatasi utilisasi POCUS jantung.
\end{abstract}

Kata kunci: Resusitasi, responsivitas cairan, syok, ultrasonografi

\section{We are Clinicians, not Ultrasound Geeks: when Cardiac Point-of-Care Ultrasonography Meets its Limitation in Guiding Fluid Resuscitation}

\begin{abstract}
Cardiac point-of-care ultrasonography (POCUS) has shown its superiority in guiding resuscitation of compromised critically ill patients. Despite its emerging usage, cardiac POCUS has limitations that should involve physical examination during its interpretation. An 84-year-old woman was admitted to the intensive care unit with hemodynamic instability following acute lower gastrointestinal bleeding. The patient appeared somnolent with physical examination revealed tachypnea, hypotension, and jugular venous distention. Laboratory data underlined no other than acute anemia. Chest radiography revealed cardiomegaly and implanted pacemaker. The patient was found hypotensive in her ward and treated with fluid bolus. In clinical reevaluation, the patient showed transient hemodynamic stability, for she underwent persistent lower gastrointestinal bleeding. Due to suspected compromised cardiac function, a cautious fluid resuscitation guided by echocardiography was commenced revealing no visible variation of the left ventricular outflow tract (LVOT) velocity-time integral (VTi), moderate aortic regurgitation (AR), and other parameters that might limit cardiac POCUS utility to assist fluid responsiveness test. We decided to administer fluid based on a regular reassessment of clinical hemodynamic parameters combined with inferior vena cava (IVC) ultrasound, Finally, the patient survived and did not suffer any complication following a large intravenous volume bolus. Intensivists' clinical assessment is paramount, especially in particular pathological conditions that limit cardiac POCUS utilization.
\end{abstract}

Key words: Fluid responsiveness, resuscitation, shock, ultrasonography

Korespondensi: Syahrul Mubarak Danar Sumantri, dr., Departemen Anestesiologi dan Perawatan Kritis, Rumah Sakit Siloam, Jember, Jl. Gajah Mada No. 106, Jember, Jawa Timur 68131,Email caliptra36@gmail.com 


\section{Pendahuluan}

Panduan resusitasi cairan dalam pemeriksaan status volume intravaskular pasien pada pasien sakit kritis terus berkembang mulai dari pemeriksaan fisis dan pengukuran parameter hemodinamik statis menuju penggunaan pointof-care ultrasonography (POCUS) jantung. ${ }^{1}$ Dengan nilai area under the curve (AUC) 0,96 serta spesifisitas $100 \%$, point-of-care ultrasonography (POCUS) jantung dianggap lebih baik dibanding dengan pemeriksaan fisis dan parameter hemodinamik statis dalam menentuan titik mula dan akhir pemberian cairan berdasar atas konsep kurva FrankStarling pada pasien sakit kritis dengan syok. ${ }^{2,3}$ Namun, perlu diperhatikan bahwa resusitasi cairan dengan panduan POCUS jantung tidak dapat dilakukan pada pasien dengan kelainan regurgitasi katup aorta serta kardiomiopati dilatasi, terkait dengan uji responsivitas cairan yang tidak valid pada populasi ini. ${ }^{4}$

Intensivis selaku penanggung jawab pelayanan resusitasi rumah sakit, mau tidak mau akan menghadapi kasus problematik berupa hipovolemia pada pasien dengan komorbid kelainan fungsi jantung. Bila tidak disertai dengan pemahaman yang cukup maka dapat jadi konsep uji responsivitas cairan dipandu POCUS jantung akan diaplikasikan secara membuta dan berakhir pada mismanajemen. Kurva pembelajaran POCUS jantung memang menanjak tajam seiring dengan peningkatan jumlah kasus yang dihadapi, namun fakta ini hanya berlaku untuk kemampuan pengambilan gambar, tidak dengan proses translasi hasil pemeriksaan. Tingkat pengetahuan dokter atas hasil pemeriksaan POCUS masuk dalam kurva berikutnya setelah proses keterampilan pengambilan gambar. Kurva kedua ini tidak menanjak, melainkan cenderung mendatar sehingga supervisi dan proses alih pengetahuan dari kasus-kasus serupa menjadi sangat penting. ${ }^{5}$

Salah satu kasus unik yang dapat menjadi bahan pembelajaran bagi sejawat intensivis dalam proses pembelajaran POCUS adalah seperti yang dihadapi penulis, pasien dengan komorbid jantung yang secara patofisiologi tidak memungkinkan dilakukan penilaian responsivitas cairan dari POCUS jantung.

Penulis belum menemukan laporan kasus serupa sehingga dirasa perlu untuk berbagi kasus ini, yaitu seorang pasien dengan diagnosis syok perdarahan akut disertai komorbid regurgitasi aorta dan kondisi jantung hipokinetik global, serta proses resusitasi pasien ini gagal dipandu oleh uji responsivitas cairan. Pada akhirnya pasien berhasil pulih setelah mendapatkan resusitasi cairan dengan hanya dipandu pemeriksaan fisis dan pengukuran parameter hemodinamik statis yang ketat.

\section{Deskripsi Kasus}

Seorang wanita berusia 84 tahun dengan berat badan 37,5 kg dirujuk dari bangsal ke unit rawat intensif (Intensive Care Unit/ICU) dengan indikasi hemodinamik tidak stabil akibat perdarahan akutgastrointestinal bawah. Pasien masuk rumah sakit dengan keluhan hematochezia dan riwayat penggunaan obat antiplatelet ganda, yaitu aspirin $80 \mathrm{mg}$ dan clopidogrel $75 \mathrm{mg}$ per hari atas indikasi riwayat serangan jantung berulang tanpa ada tindakan intervensional. Tidak ada informasi medis tambahan terkait kondisi penyakit jantung berdasar atas heteroanamnesis. Pasien ditemukan oleh dokter jaga di bangsal dalam keadaan somnolen dengan nilai oksimetri nadi perifer $85 \%$ pada udara bebas, laju napas 26-28 kali per menit, ekstremitas dingin basah, tekanan darah sistole (TDS) $70 \mathrm{mmHg}$, namun tekanan darah diastole (TDD) tidak terukur, serta nadi femoral 70 kali per menit. Meskipun tampak jelas pasien mengalami syok perdarahan, dokter jaga tidak mendapatkan peningkatan denyut jantung dan bahkan terlihat distensi vena juguler eksterna.

Pemeriksaan penunjang pasien tidak menunjukkan nilai kritis selain anemia akut, berupa penurunan hematokrit sebesar $10 \%$ dari nilai awal 34\% saat admisi. Hasil elektrokardiogram didapatkan ritme pacuventrikel 70 kali per menit. Ronsen dada pada saat admisi menunjukkan kardiomegali dan 


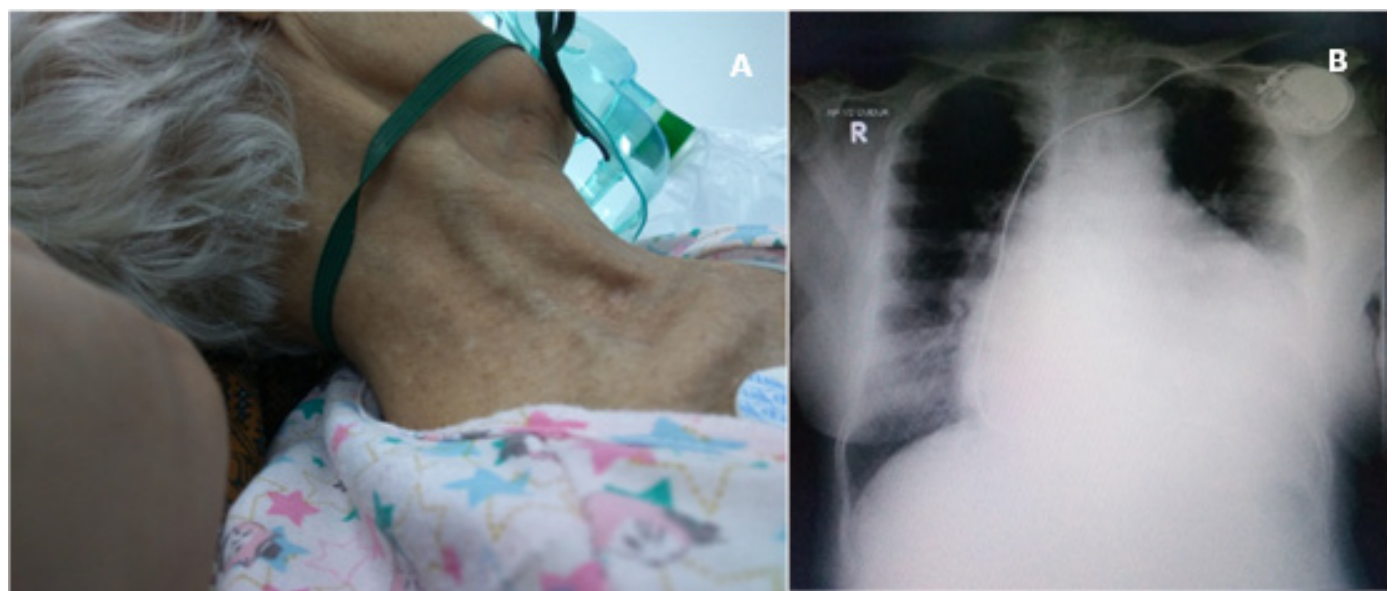

Gambar 1 Pemeriksaan Klinis (A) Distensi Vena Jugularis (B) Ronsen Dada Menunjukkan Kardiomegali dan Pacu-Jantung Tanam

pacu-jantung tanam tanpa disertai informasi setelan dasar pacu-jantung tersebut (Gambar 1).

Dokter jaga kemudian memberikan bolus $500 \mathrm{~mL}$ cairan Ringer laktat (RL) dalam 30 menit. Pada pemeriksaan klinis berulang didapatkan pasien dalam kondisi hemodinamik stabil yang transien akibat perdarahan gastrointestinal bawah yang terus berlangsung selama proses resusitasi cairan, dengan estimasi kehilangan darah sebesar $600 \mathrm{~mL}$ dalam 30 menit.

Berangkat dari dugaan keterbatasan fungsi jantung, penulis melakukan POCUS jantung di

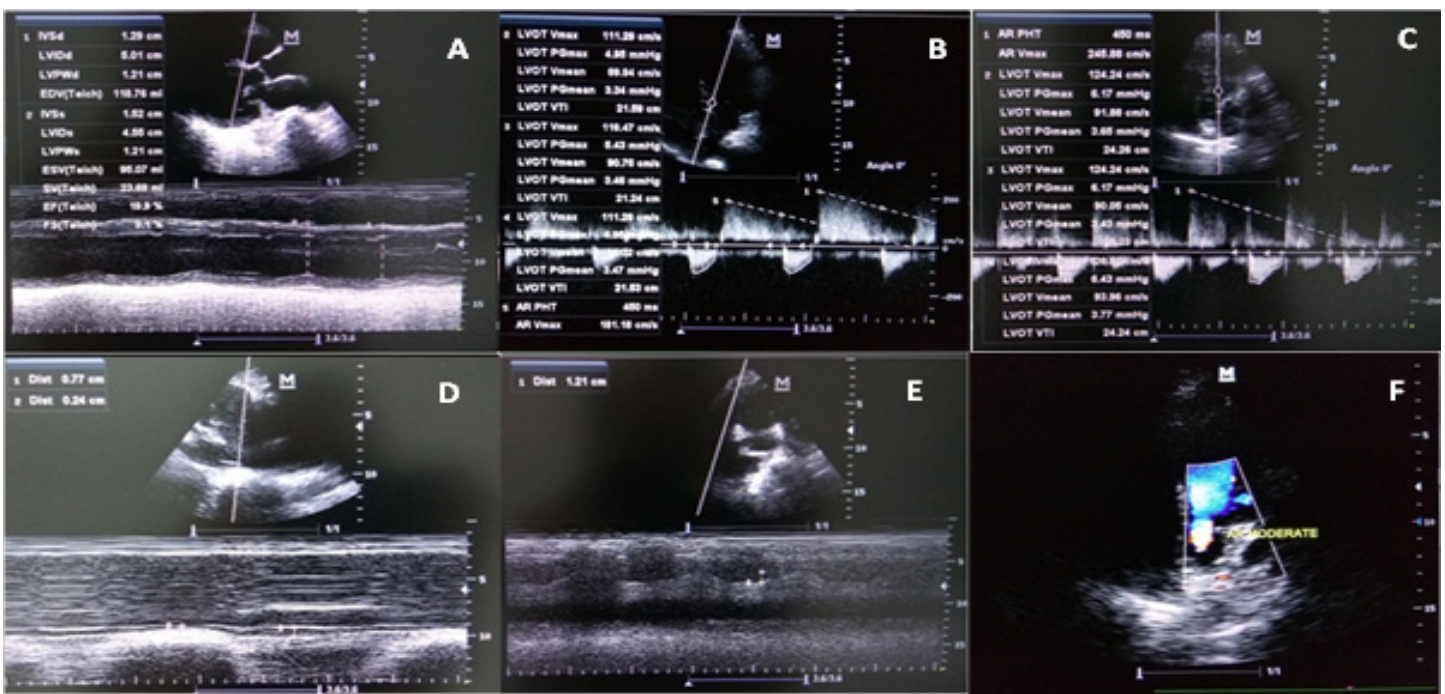

Gambar 2 Pocus Jantung Pra-Resusitasi (A) Tampilan Parasternal Long Axis pada M-Mode Lv Menunjukkan Penurunan Kontraktilitas dengan Fraksi Ejeksi 19,9\% (B) Tampilan Apical Five Chamber dengan Pulsed-Wave Doppler di Lvot Sebelum Mini-Fluid Challenge (C) Tampilan Apical Five Chamber dengan Pulsed-Wave Doppler di Lvot Sesudah Mini-Fluid Challenge Menunjukkan Variasi Vti Sebesar 11\% (D) Tampilan Subkostal pada M-Mode Ivc Menunjukkan Indeks Distensibilitas 220\% (E) Tampilan Apical Four Chamber pada M-Mode Tapse Menunjukkan Disfungsi Sistole Rv (F) Tampilan Apical Five Chamber dengan Color Flow Mapping Menunjukkan Regurgitasi Aorta Transvalvular Moderat 


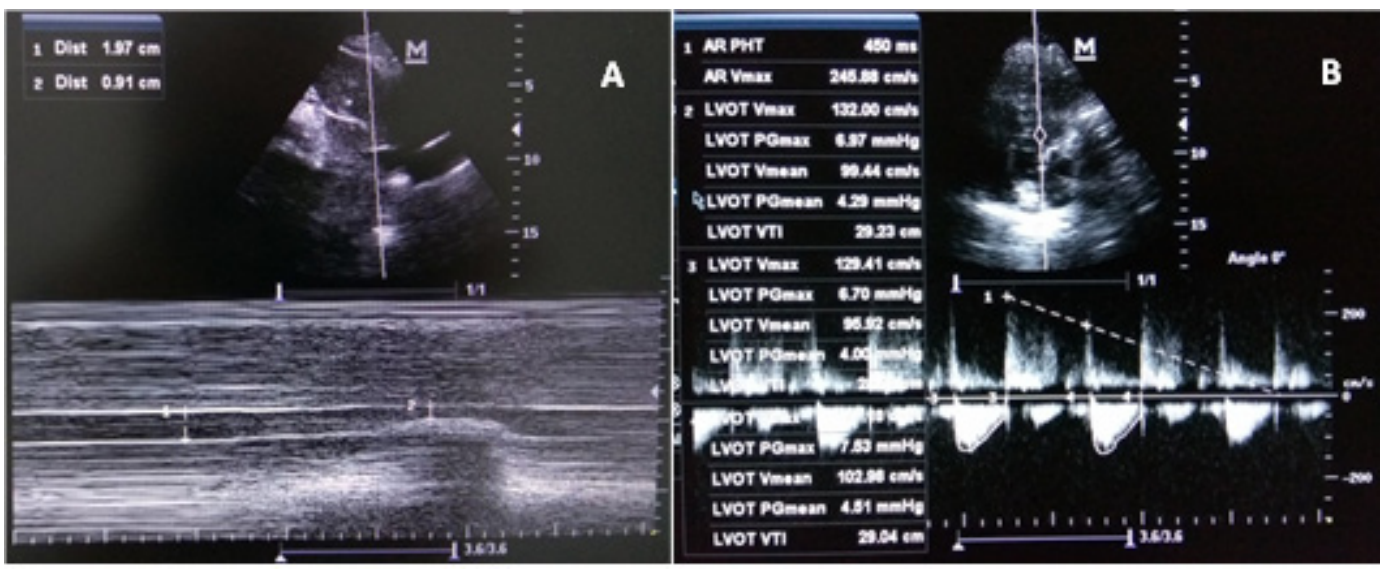

Gambar 3 POCUS Jantung Paska-Resusitasi (A) Tampilan Subkostal pada M-Mode IVC Menunjukkan Peningkatan Diameter IVC dengan Indeks Distensibilitas 116\% (B) Tampilan Apical Five Chamber dengan Pulsed-Wave Doppler pada LVOT Pascabolus Cairan $1.200 \mathrm{~mL}$ Menunjukkan Peningkatan VTi Menjadi 29,23 cm

ICU dan didapatkan kardiomiopati dilatasi dengan fraksi ejeksi ventrikel kiri (LV) 19\%, dinding jantung hipokinetik global, disfungsi sistole ventrikel kanan (RV) moderat dengan nilai tricuspid annular plane systolic excursion (TAPSE) $1,21 \mathrm{~cm}$ serta regurgitasi aorta (AR) moderat. mini-fluid challenge diberikan sebanyak $150 \mathrm{~mL}$ RL dalam 5 menit diikuti pemeriksaan left ventricular outflow tract velocity time integral (LVOT VTi) dengan variasi hanya sebesar 11\% (Gambar 2).

Memperhatikan nilai variasi LVOT VTi yang meragukan tersebut diputuskan untuk dilakukan resusitasi cairan dengan panduan pemeriksaan hemodinamik klinis yang ketat dan dibantu ultrasonografi inferior vena cava (IVC). Sebelum memulai resusitasi cairan, IVC terukur $0,24 \mathrm{~cm}$ saat inspirasi dan $0,77 \mathrm{~cm}$ saat ekspirasi.

Mengingat keterbatasan fungsi RV dan LV, penulis berpatokan pada prinsip peningkatan stress volume dengan hanya menggunakan bolus koloid serta transfusi whole blood sebesar $150 \mathrm{~mL}$ per kali pemberian disertai pengukuran tekanan darah non-invasif dan ultrasonografi IVC setiap 5 menit. Begitu pengukuran hemodinamik statis ini mencapai nilai TDS $135 \mathrm{mmHg}$, TDD $45 \mathrm{mmHg}$, dan tekanan darah rerata/mean arterial pressure (MAP) $75 \mathrm{mmHg}$, penulis menghentikan pemberian bolus cairan intravena dengan total pemberian sebesar $1.200 \mathrm{~mL}$ dalam 1 jam.

Segera setelah bolus cairan dihentikan, diameter IVC terukur $0,91 \mathrm{~cm}$ saat inspirasi dan $1,97 \mathrm{~cm}$ saat ekspirasi, serta tampak ada peningkatan signifikan nilai VTi sebesar 29,23 cm (Gambar 3). Dalam tiga jam pertama pascaresusitasi cairan, hemodinamik pasien tampak stabil dengan ekstremitas hangat kering, palpasi nadi radial 70 kali per menit teraba kuat angkat, TDS $112 \mathrm{mmHg}$, TDD 48 mmHg, serta MAP 69 mmHg. Tidak didapatkan komplikasi respirasi dan sirkulasi, yaitu upaya napas/work of breathing (WOB) normal dengan laju napas 14-16 kali per menit serta nilai oksimetri nadi perifer $96 \%$ pada udara bebas, untuk kemudian dilanjutkan dengan proses tindakan angiografi intervensi di RS rujukan.

\section{Pembahasan}

Pemeriksaan parameter hemodinamik dengan ultrasonografi telah terbukti efektif mencegah kondisi balans cairan positif yang lazim ditemukan pasca terapi cairan yang hanya dipandu parameter statis. ${ }^{6,7}$ Beberapa studi lanjutan menunjukkan tingkat morbiditas dan mortalitas yang tinggi terkait terapi cairan yang liberal disertai temuan penting bahwa resusitasi cairan berpandu tekanan vena sentral (central vena preasure/CVP) dan MAP 
memiliki akurasi yang lebih rendah dibanding dengan POCUS jantung. ${ }^{8}$ Studi tersebut memacu intensivis untuk menggunakan POCUS jantung dalam proses resusitasi pasien sakit kritis dan meninggalkan parameter hemodinamik statis. ${ }^{9}$

Euforia keadaan ini seharusnya disertai pemahaman bahwa meskipun memiliki nilai akurasi tinggi, belum ada studi yang menyatakan perbedaan signifikan luaran antara pasien yang dilakukan POCUS dan pasien yang mendapatkan pemeriksaan fisis klinisi tanpa POCUS. ${ }^{10}$ Minimnya studi yang menjelaskan keterbatasan POCUS jantung serta kemungkinan false-positive, belum lagi variasi antarpemeriksa/inter-rater variability yang tinggi maka hasil POCUS jantung perlu ditelaah secara hati-hati.

Dalam tulisannya, Blanco dkk. ${ }^{4}$ bahkan setuju bahwa pada beberapa kondisi patologis seperti kasus pasien ini, yaitu AR, kardiomiopati dilatasi dan dinding jantung hipokinetik global; POCUS jantung tidak dapat digunakan sebagai pedoman tunggal dalam resusitasi cairan. Jantung dengan komorbid seperti yang disebutkan di atas, hanya dapat dilihat secara dinamis dari ventricular pressure-volume loop dan tidak dengan pendekatan kurva end diastolic volumecardiac output. Otto Frank and Ernest Henry Starling memformulasikan kurva end diastolic volume-cardiac output untuk menjelaskan kemampuan preload dalam mengaugmentasi curah jantung/cardiac output (CO) dalam kondisi katup normal dan refleks simpatis yang tidak dimanipulasi sehingga kaidah fluid responsiveness dari POCUS jantung berdasar atas kurva Frank-Starling tidak sesuai untuk populasi pasien yang berbeda seperti pada laporan kasus ini.

Standar emas parameter dinamis uji responsivitas cairan, variasi volume sekuncup/stroke volume variation (SVV) yang dapat digantikan oleh variasi LVOT VTi dari POCUS jantung tidak dapat digunakan untuk uji responsivitas cairan pada pasien ini akibat kondisi penyerta AR moderat. ${ }^{4,11}$ Pasien dengan AR moderat-berat dapat menunjukkan hasil pengukuran LVOT VTi yang tidak akurat karena fraksi regurgitan LV akan mengaugmentasi stroke volume LV. Dengan demikian, segala peningkatan nilai LVOT VTi selama resusitasi cairan akan menjadi bias antara peningkatan SV akibat penambahan stress volume atau SV yang teraugmentasi regurgitan semata. ${ }^{12}$ Konsekuensi kondisi tersebut adalah POCUS jantung dengan pendekatan uji responsivitas cairan dari kurva Frank-Starling tidak dapat diaplikasikan. Dengan keterbatasan ini, perlu dipertimbangkan penggantian volume intravaskular dengan prinsip mini-fluid challenge dari Aya dkk. ${ }^{17}$ secara periodik disertai observasi kemungkinan kelebihan cairan atau kongesti dari pengukuran IVC.

Sebuah penelitian pernah menyatakan bahwa keberadaan pacu-jantung laju-tetap/ fixed-rate pacemaker, seperti pada pasien ini dapat mempermudah analisis uji responsivitas cairan sehubungan dengan hilangnya refleks fisiologis kardioakselerator, berupa nilai SVV yang lebih besar relatif dibanding dengan variasi curah jantung (CO); pada kenyataannya kondisi jantung pasien ini berbeda dengan populasi pada penelitian tersebut. ${ }^{14}$ Kondisi penyerta berupa dinding jantung hipokinetik global dan kardiomiopati dilatasi pada pasien ini, menyebabkan penurunan kekuatan regang LV pada saat augmentasi volume akhir diastolik (EDV) oleh mini-fluid challenge sehingga pada pemeriksaan LVOT VTi pascamini-fluid challenge tidak didapatkan variasi nilai. ${ }^{8}$

Sampai saat tulisan ini disusun, penulis tidak menemukan publikasi laporan kasus mengenai manajemen syok hipovolemik pada pasien fixed-rate pacemaker sekaligus regurgitasi aorta dan kardiomiopati dilatasi. Satu laporan mengenai syok hipovolemik pada pasien dengan pacu-jantung membahas hanya perubahan irama elektrokardiografi pra dan pascaresusitasi cairan tanpa penjelasan proses resusitasi dan pemeriksaan POCUS jantung, pun tidak jelas mengenai kondisi umum kinetika jantungnya. ${ }^{15}$

Dengan keterbatasan ilmu pengetahuan mengenai manajemen resusitasi cairan pada pasien dengan berbagai komorbid jantung seperti ini maka penulis kembali melihat salah satu potensi ultrasonografi IVC, 
yaitu identifikasi dini kongesti sistemik. ${ }^{13}$ Dengan harapan meskipun tidak memiliki panduan bagaimana memulai terapi, penulis mengetahui kapan harus berhenti memberikan cairan. Tanpa mengabaikan keterbatasan peran ultrasonografi diameter IVC pada pasien bernapas spontan yang dilakukan uji responsivitas cairan, parameter hemodinamik statis ini tidak dikontraindikasikan dalam kasus sulit seperti yang dihadapi penulis, sepanjang analisis dilakukan bersama parameter hemodinamik fisik diagnostik (TDS, TDD, MAP, perfusi ekstremitas) dan tetap dapat diukur sebelum dan sesudah dilakukan resusitasi cairan. ${ }^{4}$

Akurasi pengukuran IVC yang merupakan parameter uji responsivitas cairan boleh jadi rendah, namun bila disertai dengan pemeriksaan fisis yang ketat dan berulang,dapat digunakan sebagai pertanda kecukupan cairan intravaskular serta kongesti akibat kelebihan cairan. Terlepas dari sekian banyak kelemahannya, pemeriksaan fisis dan pengukuran parameter hemodinamik statis yang disertai interpretasi oleh klinisi harus menjadi langkah pertama asesmen pasien, dan tidak serta merta digantikan oleh pemeriksaan hemodinamik berbasis ultrasonografi seperti POCUS jantung. Penulis juga merekomendasikan penggunakan minifluid challenge pada pasien dengan syok hipovolemik dengan penyakit penyerta jantung tidak hanya sebagai sarana uji responsivitas cairan, namun juga sebagai pendekatan titrasi cairan sehingga overload cairan dapat dihindari. ${ }^{16}$

\section{Simpulan}

Beberapa pasien dengan kondisi khusus, seperti pada laporan kasus ini, tetap memerlukan keputusan klinis intensivis dalam proses resusitasi cairan hingga stabilitas hemodinamik berhasil tercapai. Terlepas dari tingkat akurasinya yang tinggi, POCUS jantung tetap hanya merupakan pemeriksaan penunjang yang menyertai pemeriksaan fisis dan klinis pasien.

\section{Daftar Pustka}

1. Parulekar P, Harris T. Assessment of fluid responsiveness in the acute medical patient and the role of echocardiography. Acute Med. 2018;17(4):236-7.

2. Kanji HD, McCallum J, Sirounis D, MacRedmond R, Moss R, Boyd JH. Limited echocardiography-guided therapy in subacute shock is associated with change in management and improved outcomes. J Crit Care. 2014;29(5):700-5.

3. Lamia B, Ochagavia A, Monnet X, Chemla D, Richard C, Teboul JL. Echocardiographic prediction of volume responsiveness in critically ill patients with spontaneously breathing activity. Intens Care Med. 2007;33(7):1125-32.

4. Blanco P, Aguiar FM, Blaivas M. Rapid ultrasound in shock (RUSH) velocitytime integral: a proposal to expand the RUSH protocol. J Ultrasound Med. 2015;34(9):1691-700.

5. Blehar DJ, Barton B, Gaspari RJ. Learning curves in emergency ultrasound education. Acad Emerg Med. 2015;22(5):574-82.

6. Boyd JH, Forbes J, Nakada TA, Walley KR, Russell JA. Fluid resuscitation in septic shock: a positive fluid balance and elevated central venous pressure are associated with increased mortality. Crit Care Med. 2011;39(2):259-65.

7. Monnet X, Marik PE, Teboul JL. Prediction of fluid responsiveness: an update. Ann Intens Care. 2016;6(1):1-11.

8. Mackenzie DC, Noble VE. Assessing volume status and fluid responsiveness in the emergency department. Clin Exp Emerg Med. 2014;1(2):67-77.

9. Pontet J, Yic C, Díaz-Gómez JL, Rodriguez P, Sviridenko I, Méndez D, dkk. Impact of an ultrasound-driven diagnostic protocol at early intensive-care stay: a randomized-controlled trial. Ultrasound J. 2019;11(1):24.

10. Smallwood N, Dachsel M. Point-ofcare ultrasound (POCUS): unnecessary gadgetry or evidence-based medicine? Clin Med J R Coll Physicians London. 
2018;18(3):219-24.

11. Bouchacourt JP, Riva JA, Grignola JC. The increase of vasomotor tone avoids the ability of the dynamic preload indicators to estimate fluid responsiveness. BMC Anesthesiol. 2013;13(1):41.

12. Laniado S, Yellin EL, Yoran C, Strom J, Hori M, Gabbay S, dkk. Physiologic mechanisms in aortic insufficiency. Circulation. 1982;66(1):226-35.

13. Beaubien-Souligny W, Rola P, Korbin K, Bouchard J, Lamarche Y, Spiegel R. Quantifying systemic congestion with point-of-care ultrasound: development of the venous excess ultrasound grading system. Ultrasound J. 2020;12(1):16.

14. Hofer CK, Senn A, Weibel L, Zollinger A. Assessment of stroke volume variation for prediction of fluid responsiveness using the modified FloTrac ${ }^{\mathrm{TM}}$ and PiCCOplus ${ }^{\mathrm{TM}}$ system. Crit Care. 2008;12(3):1-8.

15. Sparacino N, Geninatti M, Moore G. Pacemaker limitation of tachycardia in hypovolemic shock. West J Emerg Med. 2011;12(4):565-6.

16. Biais M, Courson H De, Lanchon R, Pereira B, Bardonneau G, Griton M, dkk. Mini-fluid challenge of $100 \mathrm{ml}$ of crystalloid predicts fluid responsiveness in the operating room. Anesthesiology. 2017;127:450-6.

17. Aya HD, Rhodes A, Chis Ster I, Fletcher N, Grounds RM, Cecconi M. Hemodynamic effect of different doses of fluids for a fluid challenge: a quasi-randomized controlled study. Crit Care Med. 2017;45(2):e161-8. 